\title{
A responsabilização da família brasileira a partir do desenho das políticas sociais compensatórias e focalizadas
}

The accountability of the Brazilian family from the design of focused and compensatory social policies

Aline Chiesa Gonçalves*

\begin{abstract}
Resumo:
O presente artigo visa problematizar a responsabilização das famílias brasileiras pela eficácia das políticas sociais compensatórias e focalizadas, orientadas pelo Banco Mundial, mostrando a concepção ideológica e política de tal organismo a partir das novas prescrições (1995), que foram somadas à primeira reunião do Consenso de Washington (1989). Para tanto, o trabalho será desenvolvido dentro de três eixos de análise: o primeiro corresponde ao questionamento: Qual a concepção de política social para o Banco Mundial? O segundo irá abordar um modelo brasileiro de política social compensatória e focalizada, o Programa de Transferência de Renda Bolsa Família, e o último eixo irá tratar da questão da responsabilização das famílias pela eficácia de tais políticas.
\end{abstract}

Palavras-chave: Famílias. Política social. Banco Mundial.

\begin{abstract}
:
This article intents to problematize the issue of accountability of Brazilian families for the effectiveness of focused and compensatory social policies recommended by the World Bank which displays the political and ideological conceptions of this organization from the new policies prescriptions (1995) that were added to the first meeting of Washington consensus (1989). Therefore, the work will develop in three axis analysis: What is the social policy conception for the World Bank? The second will address a Brazilian model of focused and compensatory social policy i.e. the income transfer program Bolsa Familia. The last axis will address the issue of families' accountability for the effectiveness of such policies.
\end{abstract}

Key words: Families. Social policy. World Bank.

\section{Introdução}

No Brasil e em outros países da América Latina as políticas antipobreza, dentro do contexto do desenvolvimento econômico e do ideário neoliberal pontuado com maior ênfase a partir do governo de Fernando Henrique Cardoso (1995-2002), deram novo formato às políticas sociais.

Os anos que se seguiram após as novas prescrições, em relação à intervenção estatal nas políticas sociais (1995), foram somados às intervenções firmadas na primeira reunião

\footnotetext{
* Assistente Social, Programa de Pós-Graduação em Política Social. Área Serviço Social. E-mail: chiesagoncalves@gmail.com
} 
do Consenso de Washington, em 1989, na qual uma série de recomendações que visavam o desenvolvimento econômico e a ampliação do neoliberalismo nos países da América Latina deram novas diretrizes às políticas sociais, por meio da concepção do Fundo Monetário Internacional (FMI) e do Banco Mundial.

Com esse pano de fundo, o presente trabalho propõe-se a analisar a questão da responsabilização das famílias brasileiras, mediante cumprimento de condicionalidades de políticas sociais compensatórias e focalizadas, como, por exemplo, o Programa de Transferência de Renda Bolsa Família, a partir das determinações desenhadas pelo Banco Mundial.

A questão em análise não aborda o aumento do poder aquisitivo de tais famílias, fator que, por si só, instigaria a construção de um artigo suplementar, uma vez que implica a transferência de responsabilidades do Estado em áreas como educação e saúde, para as famílias usuárias do programa. Entretanto, apesar de se tratar de um tema que abrange as políticas sociais focalizadas, parte-se de um vértice mais estrutural e de uma perspectiva de totalidade a respeito de tais políticas. $\mathrm{O}$ aspecto que despertou a ação investigativa e crítica deste trabalho é justamente a contradição existente em tais políticas, as quais podem diminuir os índices de pobreza extrema em curto prazo, respondendo a uma demanda presente na sociedade, em relação às urgências sociais, mas que não mexem nas bases estruturais que geram as desigualdades sociais, ou seja, as políticas monetárias para o desenvolvimento econômico. Segundo Raichelis (2007, p. 16):

\footnotetext{
O modelo de proteção social para pobres, no qual se inserem os programas de transferência de renda, é uma resposta necessária frente às urgências sociais, mas pontual e transitória a uma questão estrutural, portanto persistente. Responde ao presente, atendendo necessidades imediatas, adota uma perspectiva reducionista da pobreza como expressão monetária, mas não ataca seus determinantes estruturais, especialmente os relacionados à política econômica e ao modelo de desenvolvimento, mantendo inalterados os índices de desigualdade no Brasil.
}

A contradição existente entre as condicionalidades da Política de Assistência Social no Brasil e a eficácia no enfrentamento da pobreza e das desigualdades sociais tem sido pauta de longos debates cujas respostas, apesar de dados quantitativos apontarem resultados benéficos ${ }^{1}$, ainda são incertas. É preciso compreender o processo histórico e

\footnotetext{
${ }^{1}$ Revista Brasileira de Monitoramento e Avaliação (2011).
} 
suas múltiplas determinações operadas pela ordem capitalista, de como a sociedade vem estruturando-se em relação ao combate à pobreza, por meio de políticas públicas para compreender o papel da política de assistência social nos dias atuais.

Para examinar tal assunto, este trabalho fundamenta-se em outros autores que se debruçam sobre o tema na atualidade, abordando questões que fazem parte do grande emaranhado das políticas sociais no Brasil. O desenvolvimento deste trabalho movimentase entre três eixos de análise, pois o tema é amplo e necessita de delimitações.

\section{Qual a concepção de política social do Banco Mundial?}

A compreensão da influência e da intencionalidade das agências multilaterais nas políticas sociais é de extrema importância para que se possa compreender o contexto de formulação dos programas e projetos sociais brasileiros, os quais, atualmente, funcionam como ferramentas para os trabalhadores sociais.

O desenho das políticas sociais para o Banco Mundial carrega o ideário neoliberal, principalmente a partir do Consenso de Washington, em que foram formuladas, pelos organismos multilaterais e internacionais, recomendações aos países propondo um conjunto de reformas no aparelho Estatal, introduzindo a proposta neoliberal no começo da década de 1980. Assim, é reforçado o modelo que o Fundo Monetário Internacional FMI - propunha desde 1970 a alguns países, deliberando também aos países da América Latina, a partir de 1990, as políticas que deveriam ser implantadas, perante o endividamento dos países em favor da renegociação da dívida (STEIN, 1998).

Os programas de ajuste estrutural propostos pelas agências financeiras internacionais, para superar os problemas macroeconômicos, foram efetivados de forma distinta no contexto das diferentes nações. Porém, observaram-se seus impactos e suas consequências, especialmente nos países de economia periférica, dada suas demandas socioeconômicas.

Na América Latina, as particularidades sócio-históricas, a política de cada nação, suas diferentes estruturas produtivas e a inserção de suas economias no plano internacional determinaram as formas de implementação do ajuste e seus efeitos, os quais também estão ligados ao estágio de desenvolvimento do capitalismo em cada país (SIMIONATTO, 2000). 
Portanto, faz-se necessária essa compreensão para que não se reproduzam discursos moralistas, reforçados pelas diretrizes do Banco, que culpabilizam e responsabilizam os indivíduos e os diferentes arranjos familiares pela pobreza, que é inerente ao sistema capitalista. Dessa forma, de formas gerais, as propostas surgidas com o neoliberalismo apregoam a redução do papel do Estado, em contrapartida da liberdade dos mercados produtivos e financeiros, reduzindo, assim, suas funções no campo social.

Segundo Teixeira (2010, p. 673):

\begin{abstract}
Reforça-se, portanto, o papel do Banco Mundial como produtor e difusor da ideologia neoliberal (Soares; 2006). Com isso é possível ter maior clareza sobre o que escondem os fundamentos desta perspectiva, ou seja, uma deslegitimação dos direitos sociais via desresponsabilização do Estado na sua garantia. Ao reduzir o papel do Estado sob o argumento da ineficiência de suas políticas, e da sua incapacidade de provisão, defende uma perspectiva de política social que se distancia de uma noção de direitos e retorna, na forma de um conservadorismo renovado, ao mercado autorregulado e à ideologia do controle das classes populares.
\end{abstract}

A redução da pobreza à mera ausência de renda, foco dos programas de transferência de renda como o Programa Bolsa Família no Brasil, ocasiona um enfraquecimento dos direitos sociais e das discussões sobre o enfrentamento da questão social. Isto é fortalecido pela focalização e seletividade no âmbito das políticas sociais e pelo aumento das privatizações que são o carro-chefe da proposta neoliberal.

Entretanto, uma das questões importantes é o fato de que o próprio Banco Mundial e as classes dominantes reconhecem a existência e a persistência da pobreza.

O ajuste proposto pelo Consenso de Washington, então, apresentou-se como a possibilidade de solução para a situação crítica vivida pelos países e suas populações. Vale dizer que esta é a estratégia que representa as interpretações, caracterizações, concepções e interesses das classes dominantes dos países centrais e que foi conscientemente acampada pelas classes dominantes da periferia capitalista. Assim o receituário neoliberal foi posto em prática. Acontece que os ajustes estruturais, em vez de solucionarem a turbulência da luta de classes vivida na conjuntura de crise, fizeram agravá-la, trazendo soluções (podese dizer temporárias) de âmbito econômico-financeiro para as potências centrais do sistema e piorando substancialmente as condições de vida da classe operária do centro e da periferia do sistema (TEIXEIRA, 2010, p. 654).

O autor referido traz uma crítica sobre a concepção de política social do Banco Mundial e a contradição que se dá no reconhecimento, por parte das classes dominantes dos países centrais e que foi absorvida pelas classes dominantes dos países da periferia, da 
existência e da "persistência" da pobreza e da desigualdade. Portanto, essas classes, obrigatoriamente, têm de assumir que os ajustes estruturais, propostos desde o Consenso de Washington, vêm causando problemas socioeconômicos a um contingente de pessoas. Por esta razão, é possível afirmar que o empobrecimento da população não foi um processo natural apenas do sistema capitalista, mas, sim, causal, advindo de um ideal neoliberal. 0 fator da "pobreza desenfreada" causou uma grande pressão na classe formadora destes ideais com a ameaça da perda de sua hegemonia (TEIXEIRA, 2010).

Assim, o Banco Mundial influencia um modelo de política social de combate somente à extrema pobreza, objetivando o equilíbrio fiscal e monetário por meio da eficácia racionalização e redução do gasto social. A política social fica então subordinada à política econômica, sendo focalizada em grupos de risco social e aos segmentos mais vulneráveis da sociedade. Então, a partir dos princípios de seletividade e focalização dos mais pobres, a política se torna compensatória, o gasto social cada vez menor, transferindo para o setor privado a natureza dos serviços sociais e reduzindo cada vez mais as funções do Estado. Isso traz de volta o caráter de filantropia para a política social, que passa, então, a ser executada pela própria sociedade civil, gerando, assim, cada vez mais a responsabilização das famílias.

Portanto, a dimensão política de governança para o Banco Mundial passa a ter como foco a articulação de consensos na definição de prioridades e administração de conflitos, e não no combate às desigualdades sociais.

Laurell (1995) destaca que as políticas sociais no Estado Liberal não priorizam o conceito de direitos sociais, ou seja, todo cidadão, pelo simples fato de ser membro da sociedade, teria acesso por direito aos bens sociais. Mas, por conseguinte, o gozo desse benefício deve corresponder a uma contrapartida: o desempenho do trabalho mediante 0 seu pagamento. Assim, o Estado deve garantir um bem-estar mínimo somente aos comprovadamente pobres, os demais devem buscar no mercado a satisfação de suas necessidades.

A individualização da pobreza é uma estratégia adotada por este molde de política social, "deixando de ser pensada como um sistema de proteção social universal e passando a ser entendida como um conjunto de programas de atendimento aos grupos mais pobres" (MAURIEL, 2006, p. 50). 


\section{Modelo brasileiro de política social compensatória e focalizada: programa de transferência de renda bolsa família}

No Brasil, o programa Bolsa Família, criado no governo Lula após a unificação de programas remanescentes, tais como o Cartão Alimentação, Bolsa Escola e Auxílio Gás, hoje é parte do Plano Brasil Sem Miséria, lançado pela presidente Dilma Rousseff, em junho de 2011, por meio do Decreto no 7.492, o qual tem como objetivos básicos, segundo o Ministério de Desenvolvimento e Combate à Fome - MDS, a garantia de renda, de acesso aos serviços públicos e de inclusão produtiva, para garantir capacitação e inclusão no trabalho às famílias do campo e da cidade (CAMPELLO; FALCÃO; COSTA, 2014).

O Programa Bolsa Família foi criado por meio da Medida Provisória $n^{\circ} 132$ de 20 de outubro de 2003, posteriormente transformada na Lei $n^{\circ} 10.836$, incorporando o Programa Fome Zero. O Decreto $n^{\circ} 5.209$, de 17 de setembro de 2004, esclarece que a finalidade do programa Bolsa Família seria unificar os procedimentos de administração e execução de ações de transferência de renda e cadastramento único do governo federal. Sendo assim, o Cadúnico (Cadastro Único para Programas Sociais) foi instituído em julho de 2001 pelo decreto $n^{\circ} 3.887$, sendo regulamentado posteriormente pelo Decreto $n^{\circ} 6.135$, com o qual é possível, de acordo com o MDS (CAMPELLO; FALCÃO; COSTA, 2014), conhecer a realidade socioeconômica das famílias que se cadastrarem e inserir as que possuem renda per capita de até meio salário mínimo ou renda total de até três salários mínimos. Compõe a gestão e operacionalização do CadÚnico: a SENARC (Secretária Nacional de Renda da Cidadania do Ministério do Desenvolvimento Social e Combate à Fome), a Caixa Econômica Federal (CEF) e as Prefeituras Municipais.

Atualmente, o Programa de Transferência de Renda Condicionada (PTCR), Bolsa Família, é o de maior abrangência nacional, o qual consiste na transferência direta de renda, em valores que variam de acordo com a renda apresentada pela família, assim como o número de filhos em idade escolar, sendo distribuídos em duas categorias de benefícios: aquelas famílias com renda de $\mathrm{R} \$ 0,00$ a $\mathrm{R} \$ 77,00$ per capita mensal e para aquelas com renda de $\mathrm{R} \$ 77,00$ a $\mathrm{R} \$ 154,00$ per capita mensal.

Para as famílias continuarem recebendo o benefício, exige-se denominadas condicionalidades, as quais situam-se hoje nas áreas da saúde, educação e assistência social. Tais condicionalidades visam certificar o compromisso e a responsabilidade tanto 
das famílias beneficiadas como do poder público, tomando o caráter de direitos sociais básicos. Cabe ao Estado a responsabilidade pela oferta de serviços públicos de saúde, educação e assistência social e às famílias o compromisso de cumprir com as condicionalidades do programa.

A linha da pobreza é determinada, segundo o governo federal, com base em dados do censo do Instituto Brasileiro de Geografia e Estatística (IBGE) e estudos do Instituto de Pesquisa Econômica Aplicada (IPEA), abrangendo os brasileiros com renda mensal de até $\mathrm{R} \$$ 70,00 per capita e formando o público prioritário do Plano Brasil Sem Miséria (BRASIL, 2011).

A proposta dos programas de transferência de renda, em geral, é reduzir a incidência da pobreza pela insuficiência de renda. Em relação ao Programa Bolsa Família- PBF, dada sua focalização entre os mais pobres, esse objetivo, considerando resultados em curto prazo, parece estar razoavelmente sendo alcançado (SOUZA, 2011). Porém, a análise das condicionalidades nas áreas da educação e da saúde e suas relações com a eficácia na melhoria de vida dos beneficiários é um estudo para além da constatação da diminuição dos níveis de pobreza, cujos dados são gerados em longo prazo, uma vez que o programa considera que o impacto dessas condicionalidades será visível, principalmente, nas próximas gerações.

Leva-se em consideração a condicionalidade na área da educação e tem-se clareza de que o acesso aos serviços públicos de educação está garantido a crianças e adolescentes na Constituição Federal de 1988, na Lei de Diretrizes e Bases para Educação e no Estatuto da Criança e do Adolescente (ECA) e que a educação como direito fundamental para o desenvolvimento cultural, social e produtivo do indivíduo é um instrumento importante enquanto resposta às diversas manifestações da questão social. A partir disso, considerase importante analisar questões pertinentes ao acesso e permanência das crianças e adolescentes beneficiários nas escolas, visto a qualidade do ensino e serviço prestado, principalmente às camadas mais empobrecidas, as quais ficam condicionadas ao cumprimento de condicionalidades presentes no PBF, para não terem seus benefícios cortados, mas são desconsideradas sanções para o Estado pela precarização do ensino público. Neste sentido, Mônica Senna (2007, p. 93) também questiona, ao afirmar que 
[...] a perspectiva de punir as famílias, que não cumprem as condicionalidades, parece incompatível com os objetivos da promoção social do Programa. Assim não se pode deixar de considerar as condições que as famílias dispõem para atender as requisições impostas, tendo em vista às dificuldades cotidianas de sobrevivência as quais a maioria está exposta.

Na realidade, o que se verifica é que a operacionalização das condicionalidades se distancia da concepção de inclusão e promoção social e assume um caráter coercitivo.

No Brasil, o sistema educacional configurou-se historicamente como o resultado de múltiplas interações políticas, como os entes da federação, os estudantes, os movimentos sociais, as agências multilaterais e um corpo burocrático-profissional. Entretanto, é desigual a capacidade de transformar, intervir, alterar e configurar o sistema, ou seja, o poder de produzir os efeitos desejados (DUARTE, 2011).

Nos últimos 20 anos, as reformas educativas realizadas em vários países europeus e americanos coincidem com a recomposição do sistema capitalista mundial, a qual incentiva uma economia regida pela doutrina neoliberal. A educação é afetada por traços bem marcantes dessa doutrina, em que ocorreram mudanças nos processos de produção associadas aos avanços científicos e tecnológicos, à superioridade do livre funcionamento do mercado na regulação da economia e a um retrocesso no papel do Estado. Sendo assim, a prioridade da educação nos programas econômicos nos países industrializados situa-se no quadro das políticas de ajuste e de estabilização defendidas pelo Banco Mundial. Portanto, fica evidente a supremacia do desenvolvimento econômico alimentado pelo desenvolvimento técnico-científico, garantindo por si só o desenvolvimento social (LIBÂNEO, 2009).

A educação brasileira insere-se no cenário dessas transformações. Em 1990, no início do governo Collor, aconteceu a Conferência Mundial de Educação para Todos, na Tailândia, promovida pela Organização das Nações Unidas para Educação Ciência e Cultura (Unesco). Nesta ocasião foram estabelecidas prioridades para educação nos países do terceiro mundo, pontuando especialmente a universalização do ensino fundamental. Contudo, tais políticas e diretrizes não têm sido suficientes para romper com a tensão entre intenções declaradas e medidas efetivas. De um lado estabelece-se políticas educativas que visam o desenvolvimento da autonomia e da participação das escolas e dos professores, e de outro lado, porém, verifica-se a forte crise da legitimidade dos estados dificultando os investimentos em salários, carreiras, capacitações, formação docente, por exemplo, 
alegando o enxugamento do Estado por causa do déficit público, dando uma lógica contábil e economicista do sistema de ensino (LIBÂNEO, 2009).

As condicionalidades na área da saúde também passam por este entroncamento entre o acesso e a qualidade do serviço prestado, enquanto direito garantido na Constituição Federal de 1988. E sendo a política de saúde um dos tripés da proteção social no Brasil, é ainda mais preocupante quando a abordagem dessas condicionalidades se dá, apenas, em relação à vacinação e à pesagem das famílias, no âmbito materno infantil, desconsiderando os aspectos biopsicossociais dos indivíduos. Perde-se com isso a possibilidade de investir na prevenção e nos fatores que descortinariam a realidade social de cada família. Mas, historicamente, nossa cultura social é marcada por um caráter autoritário e punitivo, e a corresponsabilização das famílias, pela eficácia das políticas sociais, pode reforçar esse viés, indo na contramão da emancipação e autonomia das famílias.

Este tipo de programa enfatiza a questão do combate à pobreza como fruto das relações do trabalho dentro do sistema capitalista. Torna-se, então, necessário compreender como o Estado organiza a política social para enfrentar a pobreza, e, além disso, conhecer os resultados alcançados por esta política, isto é, a sua eficácia na prática cotidiana dos usuários. Não basta apenas fazer análise de índices e dados coletados pelos Institutos de Pesquisas, índices estes determinados por organismos externos e não pela real necessidade das populações, que, na realidade do Brasil, são as mais diversificadas levando-se em consideração a nossa extensão territorial.

Não pontuo aqui uma abordagem radical contra os programas de transferência de renda, mais precisamente ao Programa Bolsa Família, pois a contradição existente dentro do sistema capitalista sempre vai mostrar como fator emergencial a necessidade dos mais pobres versus a intencionalidade da classe dominante, dentro de um contexto histórico da sociedade.

É visto que a vida das pessoas beneficiadas melhorou em relação à renda, o que gerou um aumento do consumo e um fortalecimento do mercado. Mas do outro lado da moeda, as intervenções das políticas sociais, nos diferentes arranjos familiares, não demonstram um caráter qualitativo e tampouco de efetivação dos direitos sociais, pois não 
possibilitam a qualificação dos serviços prestados à população e, sim, a responsabilização das famílias, caracterizando, assim, dever e não direito.

\title{
A responsabilização das famílias pela eficácia das políticas sociais
}

Para tratar do tema "família" é necessário pontuar a partir de qual concepção entende-se o que é uma família. Quando ainda não se falava em nenhum programa de saúde da família no país, a enfermeira Dr. Ingrid Elsen fundou, em Santa Catarina, um trabalho que é referência na abordagem de problemáticas familiares até hoje. A autora em um de seus trabalhos escreve:

\begin{abstract}
Uma unidade dinâmica constituída por pessoas que se percebem como família que convivem por determinado espaço de tempo, com estrutura e organização para atingir objetivos comuns e construindo uma história de vida. Os membros da família estão unidos por laços consangüíneos de adoção, interesse e ou afetividade. Tem identidade própria, possui e transmite crenças, valores e conhecimentos comuns influenciados por sua cultura e nível sócio-econômico. A família tem direitos e responsabilidades, vive em um determinado ambiente em interação com outras pessoas e familiares em diversos níveis de aproximação. Define objetivos e promovem meios para o crescimento, desenvolvimento, saúde e bem-estar de seus membros (ELSEN et al., 1992, p. 6).
\end{abstract}

No desenho das políticas sociais dos dias atuais, dentro de um processo histórico, as famílias têm sido chamadas a ser parte integrante e ativa do sistema de proteção social.

A compreensão das primeiras estruturas de bem-estar social nos permite entender a posição atual da família na política social, mostrando que este fenômeno não é novo, mas que existe desde os primeiros esboços de política social no Brasil (CAMPOS, 2015). Então, mostrando a inserção da família nos primórdios da política social, Campos (2015, p. 22) desvincula esse fenômeno "apenas como consequência da política neoliberal, em ascensão a partir dos anos da década de 1990".

Entre fins do século XIX e a primeira metade do século XX, surge, como resposta às demandas do desenvolvimento acelerado gerado pelo capitalismo industrial na Europa, a primeira união entre política social e família. O que estava em jogo por meio dessa união eram as condições e as garantias para a força de trabalho e a busca por menores conflitos, garantindo a hegemonia do capital, principalmente na fase que se segue pós-guerra na reconstrução da Europa. Vários segmentos como os sindicatos, movimentos e partidos de 
trabalhadores, governos, classes médias, industriais, partidos políticos e outras organizações da sociedade estiveram empenhadas para que esse "casamento" entre a política social e a família acontecesse (CAMPOS, 2015).

O chamado Seguro Social, política de natureza contributiva, foi a primeira proposta destinada a trabalhadores com contratos de trabalho formalizados. Essa experiência deu surgimento a hoje denominada Previdência Social, destinada a combater os principais riscos sociais: doença, morte, desemprego, envelhecimento e/ou invalidez mediante transferência direta de renda às famílias feita pelos governos.

Para a experiência brasileira, esse é o marco da intervenção estatal em termos de política social que aconteceu nos anos 1930, momento em que se iniciava a industrialização da economia nacional (PAULA, 1992).

O desdobramento histórico dessa primeira experiência deu origem à política de seguridade social a partir da constituição de 1988, a qual é constituída pelo tripé: Previdência social, política de assistência social e política de saúde. Em todo esse processo de conquistas e retrocessos, a família sempre foi o fator principal das políticas sociais, pois recai sobre ela a responsabilidade de sua própria manutenção e emancipação em relação ao Estado. Segundo Adelantado (2015, p. 7):

\footnotetext{
Mediante ella (política social) pueden transformar lo que eran derechos (sanidad, educación, pensiones) en mercancías (reduciendo la intensidad protectora y desregulando el servicio público), o dejar en manos de mercado, la familia (es decir, las mujeres), o el tercer sector la respuesta a los nuevos y viejos problemas sociales (pobreza, diversificación de los tipos de familia, envejecimiento de la población, inmigración) ya sea por estar muy vigente el principio liberal del no intervencionismo o por limitaciones presupuestarias; en todo caso mediante una práctica de abandono o de inhibición.
}

Portanto, a inibição do Estado ao que se refere à garantia de direitos, haja vista a transferência de suas atribuições (saúde, educação e pensões) para o âmbito familiar, torna, assim, o acesso à proteção social pelas famílias mais empobrecidas, prejudicando, uma vez que não possuem, na maioria dos casos, os vínculos trabalhistas contributivos que são a garantia da proteção social mais ampla.

A partir da década de 1990, com a ascensão do pensamento neoliberal, que passou a dar forma às políticas sociais por meio de projetos e programas sociais, passou-se a considerar os "diferentes arranjos familiares". O antigo modelo plasmado no "chefe de 
família", reforçado pela política social contemporânea, cai em desuso (CAMPOS, 2015). Cabe, então, a cada cônjuge o cuidado e a provisão em relação aos membros da família, pois suas funções podem ser separadamente atribuídas. Não se pretende abordar a questão de gênero em relação à política social, mas cabe ressaltar que muitos programas e projetos sociais têm no papel da mãe a ênfase de sua formulação, pois, sabe-se que hoje as mulheres também são, em grande número, chefes de família.

No sentido da responsabilização das famílias, Miotto e Campos (2003, p. 170) escrevem que:

O "familismo", na expressão empregada por vários autores (em especial, EspingAndersen, 1999, p. 45; Saraceno, 1994, p. 60-81), deve ser entendido como uma alternativa em que a política pública considera - na verdade exige - que as unidades familiares assumam a responsabilidade principal pelo bem-estar social. Justamente porque não provê suficiente ajuda à família, um sistema com maior grau de "familismo" não deve ser confundido com aquele que é pró-família.

É importante analisar a abrangência do papel da família dentro das políticas sociais, sendo que o Estado não consegue assegurar, por si só, o bem-estar social.

Para os parâmetros do Banco Mundial, quanto maior o número de dependentes dentro de um núcleo familiar maior será a taxa de pobreza. São apontados ainda como os três fatores mais associados às prováveis causas da pobreza: a baixa escolaridade, a localização em uma área pobre e a família numerosa (BANCO MUNDIAL, 2001, p. 4). Mais uma vez vemos a responsabilização da família pelas altas taxas de pobreza no país, como se fosse possível fazer uma análise da consequência antes da causa, visto que é necessário analisar a pobreza a partir de uma ótica de estrutura social, política e, principalmente, econômica.

Diminuir os níveis de pobreza a partir da transferência de renda direta às famílias é uma ação necessária, visto a emergência das populações, mas não garante acesso a bens culturais, moradias decentes, meios de transporte de qualidade, postos de saúde que atendam a demanda da população, escolas qualificadas, saneamento básico, entre outras necessidades cotidianas das famílias e dos indivíduos em geral.

A transferência direta de renda, por meio de programas sociais, deveria integrar um conjunto de ações mais amplas do governo, como uma reforma tributária, por exemplo, com foco não só na redução da pobreza, mas da desigualdade social. No atual desenho, as 
políticas sociais sofrem uma desvalorização até mesmo pela classe trabalhadora, por assumirem, de certo modo, um caráter assistencialista que se reforça, mediante esta imagem deturpada pelos governos usada para controle das massas, a necessidade de práticas fiscalizatórias e punitivas, fator que anda na contramão dos direitos sociais. Sendo assim, a política social deixa de cumprir seu papel como parte de um sistema de proteção social e passa a ser vista como um conjunto de programas de atendimentos para os mais pobres. Segundo Ouriques (2005, p. 140):

\begin{abstract}
Desta forma, cabe pensar as políticas sociais para além do horizonte da mera estratégia de acomodação de conflitos ou caridade social, que requer referenciálas no processo de disputa política pelo excedente econômico real pelas massas historicamente expropriadas, de maneira que as políticas sociais não possibilitem somente reduzir as manifestações mais agudas da pobreza, através da ampliação dos serviços sociais básicos e do seu acesso, mas, sobretudo, permitam que "[...] a política social torne-se um instrumento de transformação social que mobiliza e organiza as massas a partir de seus interesses mais fortes".
\end{abstract}

Toda esta influência externa do Banco Mundial nas políticas sociais brasileiras toca diretamente nas relações familiares e no próprio formato das famílias atuais. As populações mais pobres acabam formando arranjos familiares de acordo com os condicionamentos das políticas, para que possam ter acesso a tais programas. E é neste ponto que vemos uma adequação da pobreza aos moldes do Banco Mundial, pois não basta ser pobre, mas deve-se provar sua pobreza, e cumprir com as condicionalidades da política.

A participação das famílias nas políticas sociais não deveria ser uma questão de exigência, mas de participação política em todos os níveis. Entende-se ainda:

[...] o objetivo da política social em relação à família, ou ao chamado setor informal, não deve ser o de pressionar as pessoas para que elas assumam responsabilidades além de suas forças e de sua alçada, mas o de oferecer-Ihes alternativas realistas de participação cidadã. [...]. Para tanto o Estado tem que se tornar partícipe, notadamente naquilo que só ele tem como prerrogativa ou monopólio - a garantia de direitos. Isso não significa desconsideração da chamada solidariedade informal e do apoio primário, próprios da família, mas, sim, a consideração de que essas formas de proteção não devam ser irreais a ponto de lhes serem exigidas participações descabidas e impraticáveis (SALES; MATOS; LEAL, 2004, p. 40).

Inversamente, a visão que o texto acima traz é totalmente contrária ao preconizado pela política social brasileira, que faz das famílias a grande "bengala" do capital. Responsabilizar os membros da família por romper com a pobreza geracional de uma nação 
é muito mais fácil do que desacomodar a classe dominante. Por isso, promover ações para fortalecer os laços familiares e fazer com que a família seja responsável por seus idosos e membros com deficiência e por manter suas crianças na escola e com saúde, faz com que as famílias sejam encaradas como um dos melhores recursos das políticas sociais para a regulação dos problemas sociais e para o controle dos conflitos.

\section{Considerações finais}

Diminuir os níveis de pobreza a partir da transferência direta de renda às famílias é uma ação necessária, visto a emergência das populações, contudo, ainda não garante o acesso a bens culturais, moradias decentes, meios de transporte de qualidade, escolas qualificadas que deem suporte aos alunos no processo educacional, postos de saúde que atendam as demandas da população, saneamento básico, entre outras necessidades cotidianas das famílias e dos indivíduos em geral.

A transferência direta de renda, por meio de programas sociais, deveria integrar um conjunto de ações mais amplas do governo, como uma reforma tributária, por exemplo, com foco não só na redução da pobreza, mas da desigualdade social. No atual desenho, as políticas sociais sofrem uma desvalorização, até mesmo pela classe trabalhadora, por assumirem, de certo modo, um caráter assistencialista que se reforça mediante esta imagem deturpada pelos governos usada para controle das massas. Ainda, andando na contramão dos direitos sociais, as condicionalidades impostas por tais políticas, geram práticas punitivas e fiscalizatórias. Sendo assim, a política social deixa de cumprir seu papel, de parte de um sistema de proteção social, e passa a ser vista como um conjunto de programas de atendimentos para os mais pobres.

A participação das famílias nas políticas sociais não deveria ser uma questão de exigência, mas de participação política em todos os níveis. No entanto, a realidade atual brasileira apresentada por programas como o Bolsa Família, que é um dos carros-chefes da Política de Assistência Social, gera o crescimento econômico por meio da transferência direta de renda aos extremamente pobres, aquecendo o mercado mediante o consumo e fazendo com que a grande massa de excluídos viva dentro de um padrão de meritocracia e não de conquista de direitos sociais 
Assim, a política social faz das famílias a grande "bengala" do capital. Responsabilizar os membros da família por romper com a pobreza geracional de uma nação é muito mais fácil do que desacomodar a classe dominante. Por isso, promover ações para fortalecer os laços familiares e fazer com que a família seja responsável pelos seus idosos e membros com deficiência e por manter suas crianças na escola e com saúde faz com que as famílias sejam encaradas como um dos melhores recursos das políticas sociais para a regulação dos problemas sociais e para o controle dos conflitos e responsabilizadas, de forma única, contrariando os pressupostos institucionais da educação dos filhos.

A questão da família como principal ator das políticas sociais acarreta uma desresponsabilização do Estado no provimento das necessidades sociais, o qual fica livre para fortalecer cada vez mais a manutenção da ordem vigente e do capital.

\section{Referências}

ADELANTADO, J. Las políticas sociales. Disponível em: <https://campus.usal.es/ dpublico/ areacp/materiales/6.2.laspoliticassociales.pdf>. Acesso em: 19 jan. 2015.

BANCO MUNDIAL. O combate à pobreza no Brasil: relatório sobre pobreza, com ênfase nas políticas voltadas para a redução da pobreza urbana. 2001. Disponível em: <http://web.worldbank.org/>. Acesso em: 28 ago. 2014.

BRASIL. Constituição da República Federativa do Brasil de 1988. Disponível em: <http://www.planalto.gov.br/ccivil_03/Constituicao/Constituicao.htm>. Acesso em 18 jun. 2015

Lei no 9.394, de 20 de dezembro de 1996. Estabelece as diretrizes e bases da educação nacional. Disponível em: <http://www.planalto.gov.br/ccivil_03/ Leis/L9394.htm>. Acesso em: 18 jun. 2015

. Decreto $n^{\circ} 5.209$ de 17 de setembro de 2004. Regulamenta a Lei $n^{\circ} 10.836$, de 9 de janeiro de 2004, que cria o Programa Bolsa Família, e dá outras providências. Disponível em: <http://www.planalto.gov.br/ccivil_03/_ato2004/decreto/d5209.htm>. Acesso em: 18 jan. 2015.

Portaria GM/MDS no 551, de 9 de novembro de 2005. Regulamenta a gestão das condicionalidades do Programa Bolsa Família. Disponível em: <http://www.mds.gov.br/webarquivos/legislacao/bolsa_familia/_doc/portarias/2005/Por taria\%20GM\%20MDS\%20551\%2009-11-05.pdf>. Acesso em: 1 out. 2013.

Brasil sem miséria atendera 16,2 milhões de pessoas. 2011. Disponível em: <http://www.brasil.gov.br/governo/2011/05/brasil-sem-miseria-atendera-16-2-milhoes>. Acesso em: 29 jun. 2104. 
CAMPELLO, T.; FALCÃO, T.; COSTA, P. V. O Brasil sem miséria. Brasília: MDS, 2014. Disponível em:

<http://www.mds.gov.br/webarquivos/publicacao/brasil_sem_miseria/livro_o_brasil_se m_miseria/livro_obrasilsemmiseria.pdf>. Acesso em 29 jun. 2014.

CAMPOS, M. S. O casamento da política social com a família: feliz ou infeliz. In: MIOTO, R. C. T.; CAMPOS, M. S.; CARLOTO, C. M. (Org.). Familismo, direito e cidadania: contradições da política social. São Paulo: Cortez, 2015. p. 21-43

; MIOTO, R. C. T. Política de Assistência Social e a posição da família na política social brasileira. Revista Ser Social, Brasília, n. 12, 2003

DUARTE, A. Políticas educacionais e o trabalho docente na atualidade: tendências e contradições. In: ; OLIVEIRA, D. A. (Org.). Políticas públicas e educação: regulação e conhecimento. Belo Horizonte: Fino Traço, 2011. p. 161-182.

ELSEN, I. et al. Um marco conceitual para o trabalho com famílias. Florianópolis: GAPEFAM/UFSC, 1992. Mimio.

LAURELL, A. C. Avançando em direção ao passado: a política social do neoliberalismo. In: 151-178. . (Org.). Estado e políticas sociais no neoliberalismo. São Paulo: Cortez, 1995. p.

LIBÂNEO, José Carlos. Educação Escolar: políticas, estrutura e organização/ José Carlos Libâneo, João Ferreira de Oliveira, Mirza Seabra Toschi-8.ed.- São Paulo: Cortez, 2009.(Coleção Docência em Formação/ coordenação Antônio Joaquim Severino, Selma Garrido Pimenta).

MAURIEL, A. P. O. Combate à pobreza e (des)proteção social: dilemas teóricos das "novas" políticas sociais. Praia Vermelha, Rio de Janeiro, v. 14-15, p. 48-71, 2006.

OURIQUES, N. A revolução democrática bolivariana. Uma utopia latino-americana, In: . (Org.). Raízes no libertador: Bolivarianismo e poder popular na Venezuela. Florianópolis: Insular, 2005. p. 129-151

PAIVA, B. A. Reflexões sobre pesquisa e processos de formulação e gestão. Capacitação em Serviço Social e política social. Brasília: Cead/UnB, 2000.

PAULA, L. F. R. Estado e políticas sociais no Brasil. Revista de Administração Pública, Rio de Janeiro, n. 26, p. 114-127, out./dez. 1992.

PENA, R. F. A. "Consenso de Washington"; Brasil Escola. Disponível em $<$ http://brasilescola.uol.com.br/geografia/consenso-washington.htm>. Acesso em 29 jun. 2015.

RAICHELIS, Raquel. Gestão pública e cidade: notas sobre questão social em São Paulo. Serviço Social e Sociedade, São Paulo, ano XXVIII, n. 90, jun. 2007.

REVISTA BRASILEIRA DE MONITORAMENTO E AVALIAÇÃO, Brasília: Ministério do Desenvolvimento Social e Combate à Fome, n. 2, jul./dez. 2011. 
SALES; M. A., M. C. MATOS, M. C. LEAL, (Org.). Política social família e juventude: uma questão de direitos. São Paulo: Cortez, 2004.

SARACENO, C. Mutamenti delia famiglia e politiche sociali in Itália. Bologna, Itália: II Mulino, 1998

SENNA, M. C. M. et al. Programa bolsa família: nova institucionalidade no campo da política social Brasileira? Revista katálysis, Florianópolis, v. 10, n. 1, p. 86-94, jun. 2007.

SIMIONATTO, I. Reforma do Estado ou modernização conservadora? 2000. Disponível em: <http://www.acessa.com/gramsci/?id=56\&page=visualizar>. Acesso em: 12 dez. 2014.

SOUZA, A. P. Políticas de distribuições de renda no Brasil e o bolsa-familia. 2011.

Disponível em: <http://cmicro.fgv.br/sites/cmicro.fgv.br/files/arquivos/WP_1_2011.pdf>. Acesso em 29 jun. 2014.

STEIN, R. H. Pobreza e desigualdade na América Latina sob o olhar dos organismos internacionais. Revista Serviço Social, Brasília, v. 1, p. 79-126, 1998.

TEIXEIRA, R. V. Uma crítica da concepção de política social do Banco Mundial na cena contemporânea. Serviço Social e Sociedade, São Paulo, n. 104, p.650-680, out./dez. 2010. 